\title{
Teresa Schröder-Stapper, Fürstäbtissinnen
}

\section{Falk Bretschneider}

\section{OpenEdition \\ Journals}

Édition électronique

URL : http://journals.openedition.org/ifha/10172

DOI : 10.4000/ifha. 10172

ISSN : 2198-8943

Éditeur

IFRA - Institut franco-allemand (sciences historiques et sociales)

\section{Référence électronique}

Falk Bretschneider, «Teresa Schröder-Stapper, Fürstäbtissinnen», Revue de l'IFHA [En ligne], Date de recension, mis en ligne le 17 juillet 2019, consulté le 24 septembre 2020. URL : http:// journals.openedition.org/ifha/10172 ; DOI : https://doi.org/10.4000/ifha.10172

Ce document a été généré automatiquement le 24 septembre 2020.

(C)IFHA 


\title{
Teresa Schröder-Stapper, Fürstäbtissinnen
}

\author{
Falk Bretschneider
}

\section{RÉFÉRENCE}

Teresa Schröder-Stapper, Fürstäbtissinnen. Frühneuzeitliche Stiftsherrschaften zwischen Verwandschaft, Lokalgewalten und Reichsverband, Köln, Weimar, Wien: Böhlau, 2015, 632 p., $90 €$ 
Ce n'est un secret pour personne: l'armature constitutionnelle du SaintEmpire germanique moderne était riche d'une grande variété de formes que des chercheurs travaillant sur d'autres systèmes politiques de l'époque peuvent facilement considérer comme des «bizarreries». En font certainement partie les Stifte, ressorts temporels de certains dignitaires de l'Église d'Empire qui, outre leur qualité d'autorités religieuses, étaient aussi vassaux de l'Empereur et donc princes à la tête d'une principauté ecclésiastique. Or, parmi ces territoires, certains étaient gouvernés non par des hommes, mais par des femmes, c'est-à-dire par des princesses-abbesses (Fürst-Äbtissinnen) dirigeant une abbaye immédiate d'Empire. Non seulement celles-ci administraient leur couvent, mais

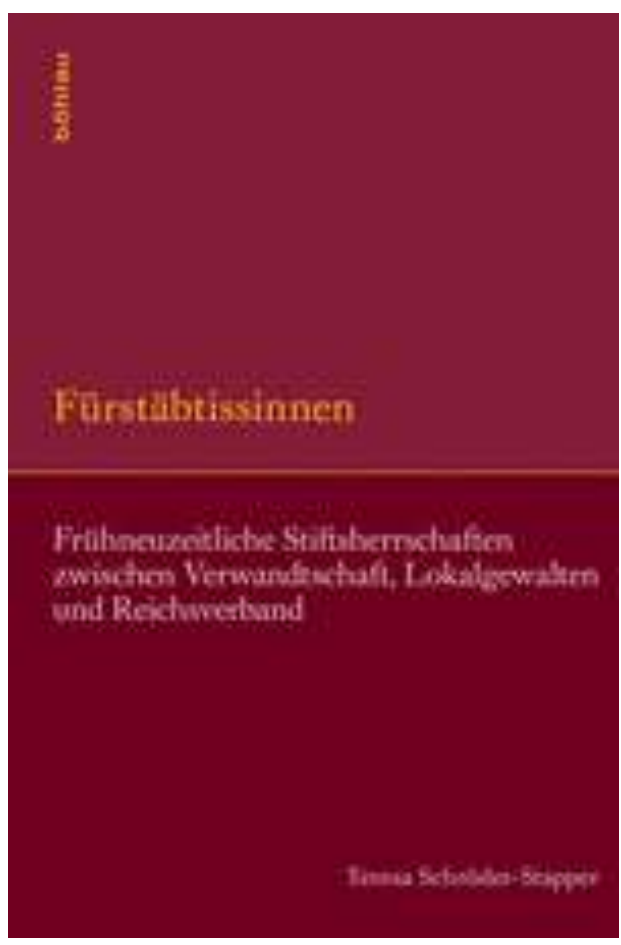
elles dominaient également un petit territoire et exerçaient même, grâce à une exemption pontificale, certains droits épiscopaux. Et, pour pousser le brouillage des catégories à l'extrême, ces institutions n'étaient pas toujours catholiques. En terre protestante, certaines d'entre elles avaient survécu à la Reforme et continuaient d'exister sous la nouvelle doctrine. Onze de ces Damenstifte demeuraient à la fin du Saint-Empire, dont trois font l'objet de l'étude de Teresa Schröder-Stapper: Herford (réformé), Quedlinburg (luthérien) et Essen (catholique).

Issu d'une thèse soutenue à l'université de Münster, l'ouvrage s'efforce d'éclairer l'histoire de ces institutions et des femmes à leur tête dans l'Empire post-westphalien sous trois angles. Il s'interroge d'abord sur les manières dont elles étaient un enjeu des stratégies dynastiques au sein de la société nobiliaire que fut le Saint-Empire. Utile réceptacle pour les nombreuses filles en excédent dans les familles de la noblesse impériale, la direction d'un Stift était l'une des rares possibilités pour une femme d'accéder à un véritable pouvoir et d'accroître ainsi l'influence de sa dynastie ainsi que les options dont celle-ci disposait sur l'échiquier politique. Les quelques dignités qui permettaient de se voir promue au rang de princesse d'Empire étaient par conséquent très convoitées et les conditions pour y accéder très strictes. Afin de réussir, tout un réseau de relations (familiales, mais aussi clientélaires ou diplomatiques) devait être mobilisé, ce qui créait de nombreuses attentes à satisfaire une fois l'élection réalisée (et des conflits si celles-ci ne pouvaient pas être honorées). Ces interdépendances se poursuivaient souvent tout au long d'un règne, en faisant ainsi des Stifte un pivot central des «politiques de la parenté » (p.159, en citant Raul Merzario) des dynasties princières dans l'Empire.

Inscrire ces institutions uniquement dans un contexte de politiques familiales ne leur rend cependant pas complètement justice. Car elles étaient également le théâtre d'un exercice du pouvoir typique du Saint-Empire: comme toute domination dans une 
principauté ecclésiastique, le règne d'une princesse-abbesse n'était rien moins qu'absolu ; elle devait non seulement composer avec le chapitre (lui-même constitué de dames issues de la haute noblesse), mais aussi avec les autorités locales et, surtout, avec l'influence du seigneur-protecteur (Schutzherr) du Stift. Dans les trois cas traités, il s'agissait du même (du moins au XVIII siècle) : le prince-électeur du Brandebourg et roi en Prusse, qui n'hésitait pas à recourir à la force militaire pour faire valoir les droits qu'il considérait être les siens. Dans une deuxième partie, T. Schröder-Stapper analyse les rapports de pouvoir complexes qui résultaient de cette situation et débouchaient régulièrement sur des scénarios conflictuels se nourrissant d'un "champ de forces " (p.165) extrêmement hétérogène. Cette alternance constante entre situations de coopération et de concurrence (p. 384) ne fragilisait pas seulement la position des princesses-abbesses, notamment à Herford et Quedlinburg où le protecteur brandebourgeois s'érigeait de plus en plus en véritable détenteur de la supériorité territoriale, elle avait aussi des répercussions directes sur les modes de gouvernement au sein des Stifte et les formes de représentation du pouvoir qui y avaient cours. En fait, tout en voyant leurs marges de manœuvre concrètes se réduire progressivement, les princesses-abbesses furent maintenues dans leur rang, ce qui fait de leur domination un exemple typique des contradictions et paradoxes qui marquaient la situation du Saint-Empire dans les dernières décennies de son existence.

Cette continuité de l'existence des Stifte était évidemment liée à leur qualité de fiefs immédiats d'Empire. La troisième partie du livre s'intéresse par conséquent aux relations qu'ils entretenaient avec le niveau impérial, à leur participation aux rituels d'Empire (et notamment à celui de l'investiture, particulièrement important pour légitimer le pouvoir de potentates dont les prérogatives se fondaient sur une simple élection), à leur présence à la Diète à Ratisbonne ou aux recours fréquents que les princesses-abbesses faisaient à la justice impériale afin de rétablir leur position régulièrement mise en cause. L'auteure y fait ressortir l'importance fondamentale de l'Empire pour l'existence même de ces États mindermächtig ("de moindre puissance »), constamment menacés par l'avidité de leurs voisins plus forts et donc obligés, par instinct de survie, de concourir au maintien de la structure impériale au moyen d'interminables tractations d'autant plus complexes que, dans ce jeu, l'Empereur n'était pas lui-même un acteur neutre. Comme souvent, les conflits n'étaient pas résolus mais suspendus - ce qui ne faisait triompher personne mais évitait le pire : la médiation par l'insatiable « protecteur » prussien.

En définitive, il s'agit donc d'une étude qui contribue surtout à notre connaissance des rouages du politique dans le Saint-Empire et notamment de l'organisation du pouvoir dans ces micro-territoires que l'historiographie a longtemps considérés, avec dédain, comme les meilleures illustrations du caractère suranné de l'ensemble impérial. Derrière ces analyses, qui s'appuient sur un riche matériau provenant d'une vingtaine de dépôts d'archives, disparait pourtant un peu la question du genre et de l'exercice du pouvoir féminin. Néanmoins, le mérite revient à l'auteure d'avoir attiré l'attention de la recherche sur ce qui passait jadis pour une simple curiosité - et qui était pourtant l'un des révélateurs les plus parlants d'un système politique dont les modes de fonctionnement étaient peut-être plus représentatifs de l'époque moderne qu'on ne le croit. 
INDEX

Index chronologique : Période moderne

Thèmes : Histoire des États et des pouvoirs, Histoire des femmes, histoire du genre

\section{AUTEURS}

FALK BRETSCHNEIDER

EHESS Paris 